\title{
Phonoenterography: the recording and analysis of bowel sounds
}

\author{
W. C. WATSON AND ELIZABETH C. KNOX \\ From the University Department of Medicine, Glasgow Royal Infirmary, and the \\ Acoustic Division of the Regional Physics Department
}

EDITORIAL COMMENT Bowel sounds, seemingly so simple on auscultation, become a very complex and poorly understood sign when submitted to a scientific study. Further correlation with clinical syndromes is needed. This technique offers a simple method, and one without any discomfort to patients, for studying effects of drugs affecting bowel mobility.

Bowel sounds are physical phenomena which can be recorded, illustrated, measured and analysed, and thereafter correlated with associated physical phenomena.

The terms used by clinicians to describe bowel sounds are either subjectively qualitative (tinkling, high-pitched) or crudely quantitative (present, absent, loud, frequent, increased, diminished). None of three popular British textbooks of gastroenterology lists bowel sounds or abdominal auscultation in its index, and even Bockus (1964) has only half a column on the subject.

Cannon (1905) wrote the first systematic account of abdominal auscultation in relation to the structure and function of the stomach and intestines. The best clinical papers since then have been those of Stevens (1936) and Milton (1958).

The first attempt to make visual records of bowel sounds seems to have been that of Du Plessis (1954), who used a phonocardiograph. His results were of very limited value. Farrer and Ingelfinger (1955) used more elaborate equipment, including an oscilloscope for direct vision of the linear pattern of the sound waves, and an integrator which summated sound energy during each 30 seconds of recording. With this apparatus they demonstrated that sound recording could in certain circumstances be as useful as balloon kymographic techniques for the study of intestinal motility.

In spite of this development, Wells, Rawlinson, Tinckler, Jones, and Saunders (1961 and 1964) observed that 'the conversion of bowel sounds to a visual record is as yet imperfectly developed' and themselves used simple auditory analysis of tape recordings of bowel sounds in association with kymographic and radiological data, in their studies on postoperative gastrointestinal motility.
The recent paper by Horn and Mynors (1966) reports another instrumental approach to the problem of bowel sound recording. Although this is possibly an advance on the techniques of Farrer and Ingelfinger (1955), the spectogram which their apparatus produces is a complex record which is difficult to understand, and the frequency range of their apparatus is probably too small.

In this paper we describe the apparatus and techniques which we have used for the recording and analysis of bowel sounds, list some of their properties, and consider critically the possible uses of phonoenterography.

\section{RECORDING APPARATUS}

MICROPHONE ${ }^{1}$ Suction microphone, crystal inset, for use with phonocardiograph amplifier 642 . Skin area $12 \cdot 5 \mathrm{~cm}^{2}$. This microphone, which was only partially successful for phonocardiography, because of its poor response to very low frequency sounds, is very satisfactory for the higher frequency range of bowel sounds.

AMPLIFIER Levell TM2, with a frequency response of 30 to $30,000 \mathrm{c} / \mathrm{s} \pm 0 \cdot 1 \mathrm{db}$.

TAPE RECORDER Brenell mark 5M, with a recording/ replay frequency response of 40 to $18,000 \mathrm{c} / \mathrm{s} \pm 3 \mathrm{db}$. at a tape speed of $7 \frac{1}{2}$ in./sec.

Standard acoustic analysis of this system showed true recording and true reproduction of sounds with a frequency range of 90 to $7,000 \mathrm{c} / \mathrm{s}$, within the limitations of the microphone, which tends to resonate at 2,000 and $4,000 \mathrm{c} / \mathrm{s}$.

\section{RECORDING METHOD}

Usually the patient lay supine, but when recordings were made during meals the semi-recumbent position was ${ }^{1}$ Manufacturer NEP, now Honeywell 
used. The microphone was firmly attached to the skin and nothing else allowed to touch it. Recordings were not made if extraneous sounds were being monitored, or if such sounds obtruded into a recording they were identified and noted, e.g., the clinking of a spoon on a plate.

The amplifier earth was discarded since it acted principally as an aerial for the hospital's call signal.

All recordings were made at a tape speed of $7 \frac{1}{2}$ in./sec., but from the information obtained from these studies a tape speed of $3 \frac{3}{4}$ in./sec. should be satisfactory.

Initially four auscultatory areas were used: midepigastrium (stomach, area I), right lower epigastrium (pyloroduodenal, area II), infra-umbilical (small bowel, area III), and left iliac fossa (descending and sigmoid colon, area IV). But it was soon obvious that the bowel sounds were propagated over wide areas, and that surface anatomy was not a sufficient guide to the origin of sounds. Thereafter, areas II and III were mainly used without implying that the sounds heard at them were solely of gastroduodenal or small bowel origin.

Recordings were taken from normal subjects and patients with a variety of alimentary conditions, fasting, during, and at intervals after meals. This was done to get information on the range and variety of sounds which would be encountered.

\section{ANALYSIS}

For the complete acoustic analysis of sounds two methods are necessary.

APPARATUS FOR METHOD I A block diagram of the apparatus is shown in Figure 1.

Tape recorder Ferrograph series 5, with a playback response of 40 to $15,000 \mathrm{c} / \mathrm{s} \pm 3 \mathrm{db}$. at a tape speed of $7 \frac{1}{2} \mathrm{in.} / \mathrm{sec}$.

Octave band analyser (O.B.A.) Two types of octave band analyser were used: (1) Dawe, type 1410, in-
TABLE I

OCTAVE BANDS CORRESPONDING TO THE CENTRE FREQUENCY SETTINGS OF THE BRUEL AND KJAER ANALYSER ${ }^{1}$

Octave Band $(c / s)$

Centre Frequency $(c / s)$

$\begin{array}{rrr}88- & 176 & 125 \\ 177- & 354 & 250 \\ 354- & 708 & 500 \\ 707- & 1,414 & 1,000 \\ 1,414- & 2,828 & 2,000 \\ 2,828-5,656 & 4,000 \\ 5,656-11,312 & 8,000\end{array}$

${ }^{1}$ Derived from the formula $f_{1}=\frac{1}{2} f_{2}=\frac{\text { Centre frequency }}{\sqrt{ } 2}$

corporating o.b. ranges of 75 to 150,150 to 300 , up to 4,800 to $10,000 \mathrm{c} / \mathrm{s}$; (2) Bruel and Kjaer type 1613 . The octave bands corresponding to the centre frequencies of this analyser are given in Table $\mathbf{I}$.

Level recorder Bruel and Kjaer type 2304. Paper speeds used were 1,3 , and $10 \mathrm{~mm}$./sec. Writing speeds used were 100 and $200 \mathrm{~mm}$./sec. The intensity range of the instrument is 50 decibels.

The tape recording is played through the octave band analyser which is set to select a particular frequency range. The sounds within this range are charted by the level recorder. The height of the sound waves is a measure of their relative intensity above background, while the horizontal record shows the duration and rate of occurrence or rhythm of the sounds.

At slow paper speeds this method gives a general representation of sound patterns or sequences, and at fast paper speeds a more detailed record of individual sounds.

For more detailed analysis of individual sounds of finite duration a second method of analysis is required.

APPARATUS FOR METHOD II A block diagram of the apparatus is shown in Figure 2. The main new item of

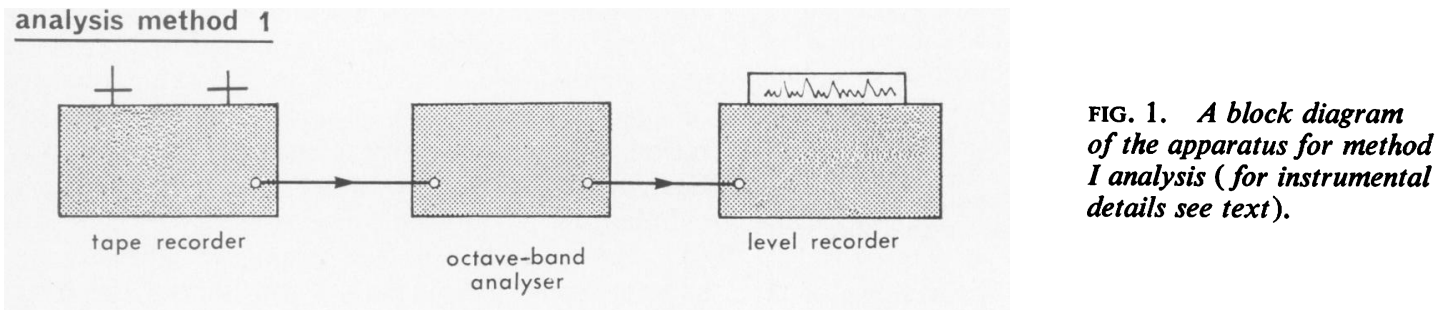

results

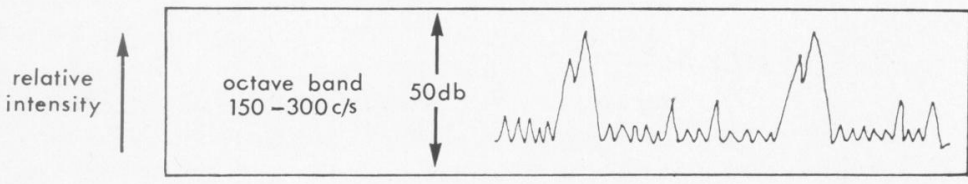

time 


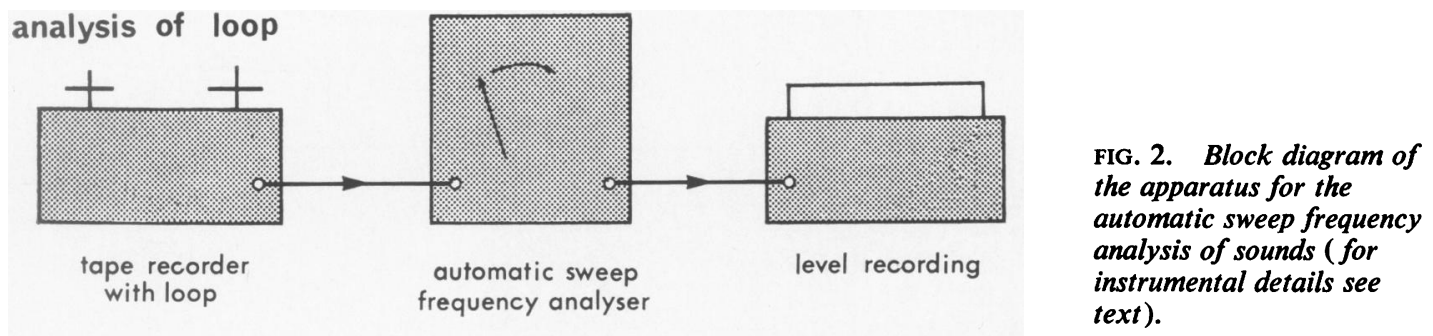

results

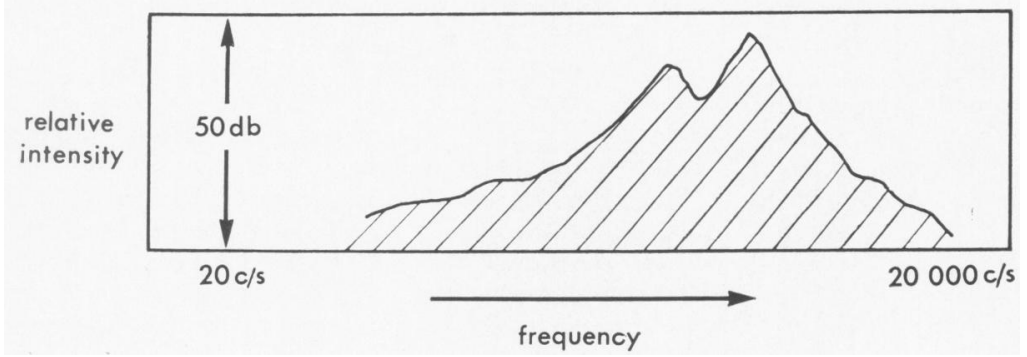

equipment in this apparatus system is the automatic sweep frequency analyser (Bruel and Kjaer, type 2107).

The sound to be analysed is selected and recorded on a continuous loop of tape, which is only a few inches long. This loop is played continuously over and over again, and the sound is filtered at a constantly rising frequency by the automatic sweep frequency analyser (Fig. 2). This produces a record in which the height of the waves represents relative intensity, and the horizontal record represents rising frequency.

Examples of such records are shown in Figs. 4 and 5. The first step in the understanding and interpretation of these automatic analyses is to realize that each complete wave form, $1.5 \mathrm{~mm}$. wide, is a separate record of the same sound. As the frequency (c/s) rises, the intensities of the many components of this sound vary in characteristic ways which produce separate, identifiable curves. The final record incorporates a variable number of these subsidiary curves.

Figures 4 and 5 differ not only in the shape of the curve of the highest intensity, but also in the shapes of the subsidiary curves. Each record has so much detail that it is, in a sense, a finger print of the sound analysed.

\section{RESULTS}

Three examples of method I analysis are illustrated in Figure 3.

Figure $3 a$ is of sounds recorded at area II, at the end of a main meal eaten by a patient with a duodenal ulcer. The sounds, almost certainly due to gastro-pyloric peristalsis, were of regular rhythm, rising pitch, and crescendo intensity, that is, each sound seemed to become louder during the first three-quarters of its duration. The figure illustrates the regular rhythm, the similar duration, and the fairly equal intensity of the sounds.

Figure 4, which is the automatic sweep frequency analysis of one of the sounds from Fig. 3a, shows that the crescendo impression is not an auditory illusion due to rising pitch, for the higher frequency components of the sound are of greater intensity.

Figure 3b illustrates sounds recorded at area III in a middle-aged woman, three days after removal of an ovarian cyst. The sounds, probably of small bowel origin, were irregular and very unusual. Each consisted of a short preliminary gurgle, culminating in an explosion of sound which was followed by a high-pitched echo. The figure demonstrates the irregular rhythm and variable intensity of the sounds, and Fig. 5 is the automatic sweep frequency analysis of one of these sounds.

Figure $3 c$ illustrates the sound pattern recorded at area III in a woman whose clinical problem was intestinal 'hypermotility'. The sounds are frequent, irregular, and of variable intensity. In each of the records of Fig. 3 the baseline is the sound rerecording of abdominal aortic pulsation.

By increasing the paper rate the record can be expanded, and more detail revealed. Figure 6 illustrates this for the sound E2 of Figure $3 \mathrm{~b}$. This shows 
level recordings. speed $-1 \mathrm{~mm}$./ second

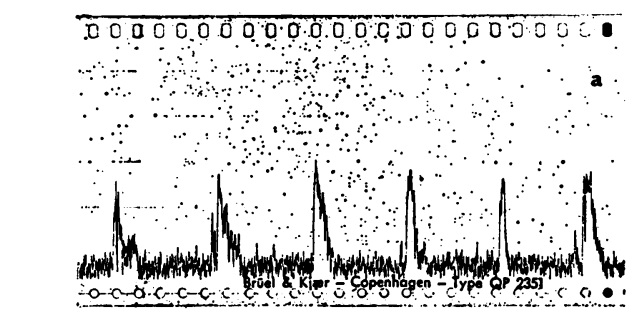

FIG. 3. Examples of level or linear recordings by method I analysis of sounds recorded (a) at area II in a man with duodenal ulcer, in the course of a main meal; $(b)$ at area III in a middle-aged woman, three days postoperatively; and (c) at area III in a woman with hypermotility disorder of the small bowel.

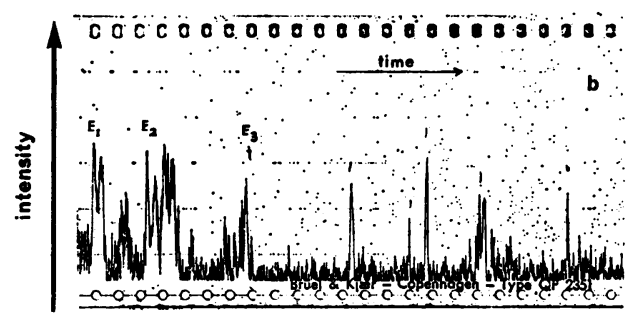

FIG. 4. An automatic sweep frequency analysis of one of the sounds in Figure $3 a$.

FIG. 5. An automatic sweep frequency analysis of sound E1 in Figure $3 b$.

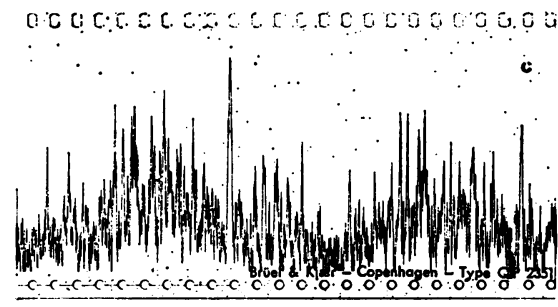

FIG. 3.

time

Mr McL.

automatic analysis of a "crescendo" speed $-1 \mathrm{~mm}$./second

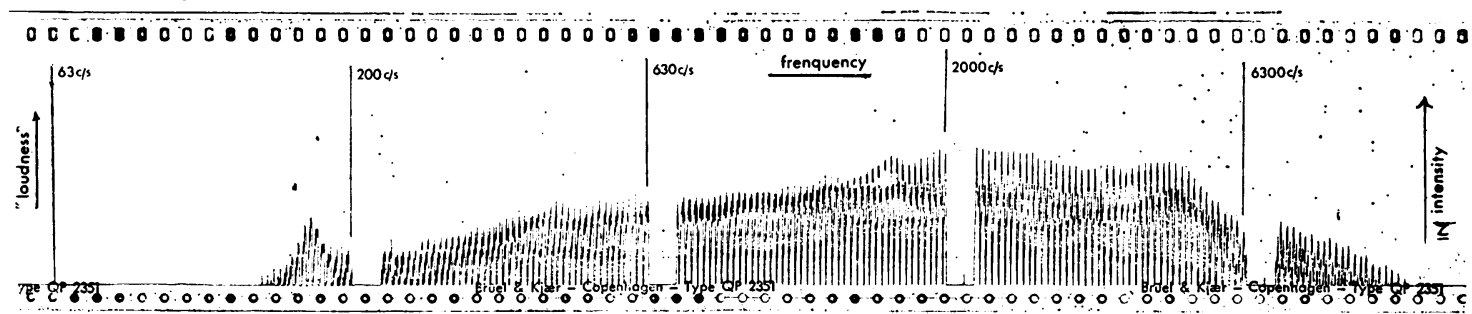

FIG. 4.

\section{Mrs M.S.}

automatic analysis of E.1 speed $-1 \mathrm{~mm} / \mathrm{second}$

30000000000000000000000000000 frequency 000000000000000000000000000000

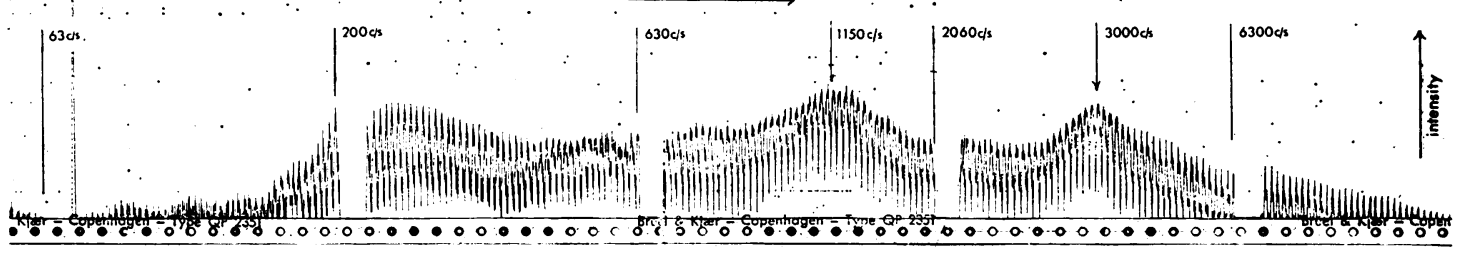

FIG. 5. 
level recordings. speed $-10 \mathrm{~mm}$. $/$ second

$0.8 .75-150 \mathrm{c} / \mathrm{s}$

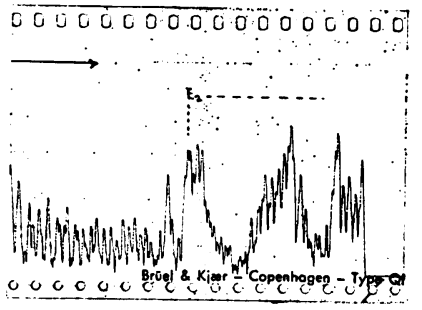

level recording. speed $-10 \mathrm{~mm}$. second OB. $300-600 \mathrm{c} / \mathrm{s}$

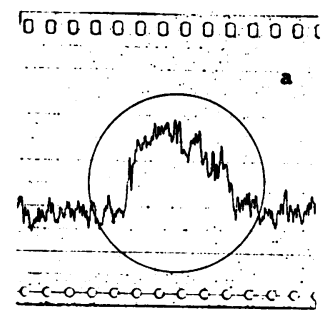

OB. $600-1200 \mathrm{cts}$

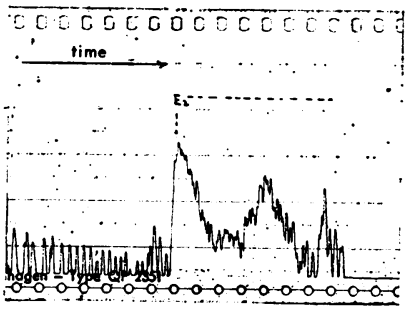

FIG. 6. Expanded linear records of sound E2, illustrating the variable intensities of the component peaks at different octave bands.

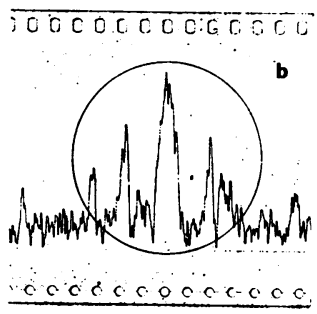

FIG. 7. Expanded linear records reveal distinct visual differences between sounds which seemed similar on auscultation. not only that the sound has three peaks but also, when different octave bands are selected, that these peaks are of variable relative intensity.

The expanded record may show differences between sounds which, on auscultation, seemed similar. Figure 7a illustrates expanded records of one of the sounds of Fig. 3a, and Fig. 7b an apparently similar sound from another male patient in similar circumstances. But the expanded record may also demonstrate visual similarities between sounds, as in Figure 8.

Finally, Fig. 9 illustrates the quantitative comparison of bowel sounds. The series of four records shows how the intensity of the bowel sounds increased during a meal, and remained higher than the preprandial level two hours later.

PROPERTIES OF BOWEL SOUNDS By inspection and quantitative analysis of the records it is possible to list the following properties of bowel sounds.

They are complex, that is, none of them is a pure tone. Each comprises a mixture of tones. Further, a 'bowel sound' is often a sequence of closely connected sounds (Figs. 6 and $7 \mathrm{~b}$ ).

They have a frequency range of at least 150 to $5,000 \mathrm{c} / \mathrm{s}$.

They have an intensity range of 34 to $40 \mathrm{db}$ above background.
TABLE II

DURATION OF AND INTERVAL BETWEEN 'CRESCENDO' SOUNDS

\begin{tabular}{|c|c|c|c|}
\hline \multicolumn{2}{|l|}{ During Soup } & \multicolumn{2}{|c|}{ During Main Course } \\
\hline $\begin{array}{l}\text { Duration } \\
(\mathrm{sec} .)\end{array}$ & $\begin{array}{l}\text { Interval } \\
\text { (sec.) }\end{array}$ & $\begin{array}{l}\text { Duration } \\
\text { (sec.) }\end{array}$ & $\begin{array}{l}\text { Interval } \\
\text { (sec.) }\end{array}$ \\
\hline 3 & & 1 & \\
\hline 3 & 5 & & 15 \\
\hline & 9 & & 12 \\
\hline 2 & 8.5 & 5 & 14 \\
\hline 2 & & 3 & \\
\hline 2 & 8 & 2 & 16 \\
\hline & 9 & & 15 \\
\hline 0.5 & & 6 & \\
\hline 2 & $8 \cdot 5$ & $5 \cdot 5$ & 18 \\
\hline & 9 & & 17 \\
\hline 2 & $7 \cdot 5$ & 4 & 20 \\
\hline 3 & & 6 & \\
\hline & $9 \cdot 5$ & & 16 \\
\hline 1 & 7 & 5 & \\
\hline 2 & & $4 \cdot 5$ & 15 \\
\hline 4 & $7 \cdot 5$ & & 16 \\
\hline & 5 & 5 & 16 \\
\hline 6 & & 3.5 & \\
\hline 4 & 6 & 4.5 & 15 \\
\hline 2 & 5 & & 15 \\
\hline $\begin{array}{l}2 \\
\text { Average } 2 \cdot 6\end{array}$ & & 5 & \\
\hline Average $2 \cdot 6$ & 6.9 & $4 \cdot 3$ & $15 \cdot 7$ \\
\hline
\end{tabular}




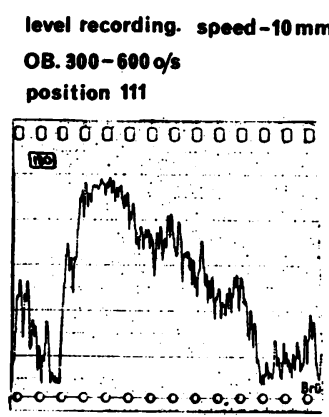

\% age 39

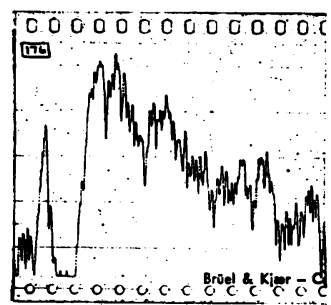

O’age 54
FIG. 8. Expanded linear records demonstrate close visual similarities between sounds which seemed similar on auscultation.

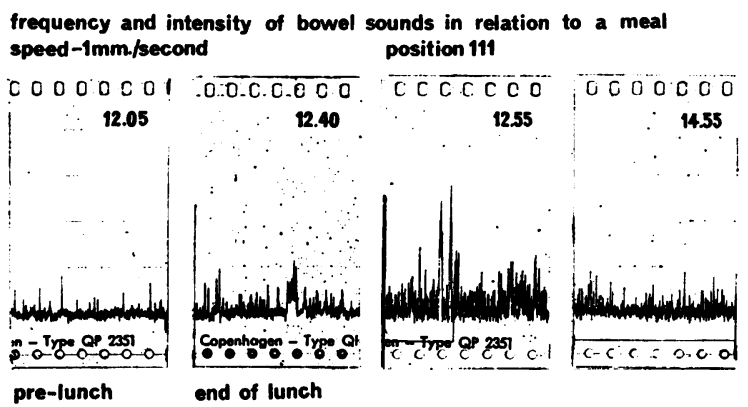

FIG. 9. Sequential quantitative comparisons of bowel sounds are possible using linear records.
They may be of regular or irregular rhythm. Even when regular, however, they are by no means comparable to the regularity of heart sounds. Table II shows that the interval between the sounds of wellestablished gastric peristalsis varies from 12 to 20 seconds, and this is perhaps the most regular pattern of sound which is encountered. It is interesting that although Cannon's typical ' 20 second' gastric sound cycle occurs late in the meal, at the start of the meal the average duration is 9.5 seconds. As the sounds become longer the interval between them also lengthens.

Because they are occurring more rapidly, the small bowel sounds appear fairly regular (Fig. 3c), but an expanded record disproves this impression.

The duration of sounds varies considerably. The longest are the gastro-pyloric sounds with a range of 0.5 to 6.0 seconds, and the 'echo-explosion' sounds of Fig. 3b with a range of 7 to 10 seconds. In the case of the latter, however, it is difficult to know whether to regard them as one sound or as a group of closely placed sounds (Fig. 6).

The shortest sounds are the high-pitched'tinkling' sounds of Fig. 9 with a range of 0.2 to 0.5 seconds. It is possible that there are shorter sounds than these, outside the capacity of the equipment to cope with very short sounds.
The interval between sounds tends to be directly related to the length of the sounds (sse Table II). Thus, the interval between the very short tinkling sounds is about 0.2 seconds, whereas between the long sounds of gastric peristalsis it ranges from 12 to 20 seconds.

They have wide surface propagation, and therefore there is a tendency for sounds of different origin to be superimposed on one another. However,

\section{TABLE III}

CONDITIONS AFFECTING THE PROPERTIES OF BOWEL SOUNDS

\begin{tabular}{ll} 
Sound Property & Structural and Functional Conditions \\
\hline Frequency $(\mathrm{c} / \mathrm{s})$ & $\begin{array}{l}\text { Dimensions of bowel segment } \\
\text { Contents of lumen } \\
\text { Thickness of wall }\end{array}$ \\
Intensity & $\begin{array}{l}\text { Force of contraction } \\
\text { Conducting material } \\
\text { Distance from source }\end{array}$ \\
Rhythm & Rate of contractions
\end{tabular}

the sounds which originate closest to the microphone tend to predominate, so that by suitable adjustment of the recording level some degree of anatomical selection is possible. 


\section{DISCUSSION}

The physical conditions which determine the properties of bowel sounds are listed in Table III. This empirical, but obvious, arrangement of causes and effects includes structural and functional characteristics of the gastrointestinal tract and its surroundings, all of which are ultimately capable of measurement and description.

Theoretically, therefore, it seems that it should be possible to relate the precise properties of a bowel sound, or series of sounds, to precise structural conditions and functional events within the alimentary tract. Thus, certain aspects of bowel motility and pressure may be predictable, without intubation, from the rhythm and intensity of the bowel sounds which they produce.

Farrar and Ingelfinger (1955) have already demonstrated that in certain circumstances the energy and number of bowel sounds correlates well with kymographic data, and with their apparatus they showed the stimulant effect of prostigmine and the inhibitory effect of mepiperphenidol bromide on small bowel activity. It is this aspect of bowel sound recording which seems to us to have the most useful potential in the development of a simple, yet accurate, method for studying the clinical pharmacology of drugs affecting intestinal motility, and one which avoids the discomfort and delay of intestinal intubation.

Farrar and Ingelfinger (1955) state that the presence of gas is 'essential' for the production of bowel sounds, but we would dispute this. The prime requisite for the production of a sound wave is a vibrating object and a transmitting medium, which need not be gaseous. There is certainly no gas contributing to heart sounds and murmurs. It is probably true that gaseous distension of loops of bowel will cause the sounds to be louder, and it will certainly affect the frequency (c/s) or pitch of the sounds. But the energy for sound production comes from the contraction of the muscle, and it is only insofar as gas stretches muscle fibres that it affects sound energy.

It is possible that bowel sound analysis might be useful in the diagnosis of motility disorders such as that described by Connell, Jones, and Rowlands
(1965), but before this can be assessed it requires the correlation of sound and motility data by simultaneous recording. We have not yet been able to do this. The next step must be a systematic correlation of normal and pathological anatomy and physiology with the visible spectrum of bowel sounds which can be obtained by the methods we have described.

The sample records illustrated in this paper make it clear that there is more detail in bowel sounds than is apparent to the unaided ear. It remains to be seen how far this detail can be applied to improved diagnosis of intestinal disorders, and to the study of intestinal function and pharmacology.

\section{SUMMARY}

Apparatus for the recording and analysis of bowel sounds is described in detail. Typical and representative records are illustrated and explained, and data on the frequency $(\mathrm{c} / \mathrm{s})$, relative intensity $(\mathrm{db})$, rhythm, and construction of bowel sounds are presented.

The structural and functional properties of the gastrointestinal tract which affect the properties of bowel sounds are listed, and the possible uses of phonoenterography for the study of intestinal function and pharmacology are briefly discussed.

\section{REFERENCES}

Bockus, H. L. (1964). Gastroenterology, 2nd ed., Vol. 2, p. 355. Saunders, Philadelphia and London.

Cannon, W. B. (1905). Auscultation of the ryhthmic sounds produced by the stomach and intestines. Amer. J. Physiol., 14, 339-353.

Connell, A. M., Jones, F. A., and Rowlands, E. N. (1965). Motility of the pelvic colon. Part IV. Abdominal pain associated with colonic hypermotility after meals. Gut, 6, 105-112.

Du Plessis, D. J. (1954). Clinical observations on intestinal motility. S. Afr. med. J., 28, 27-33.

Farrar, J. T., and Ingelfinger, F. J. (1955). Gastrointestinal motility as revealed by study of abdominal sounds. Gastroenterology, 29, 789- 800 .

Horn, G. E., and Mynors, J. M. (1966). Recording the bowel sounds. Med. biol. Engin., 4, 205-208.

Milton, G. W. (1958). Normal bowel sounds. Med. J. Aust., 2, $490-493$.

Stevens, N. C (1936) Auscultation of the abdomen. New Engl. J. Med., 215, 22-26.

Wells, C., Rawlinson, K., Tinckler, L., Jones, H., and Saunders, J. (1961). Ileus and postoperative intestinal motility. Lancet, 2, 136-137.

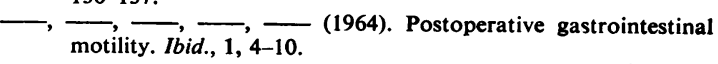

